\title{
PERANCANGAN APLIKASI PEMESANAN MAKANAN DAN MINUMAN PADA RUMAH MAKAN CEPAT SAJI D'BESTO
}

\author{
Heri Setiawan $^{1}$, Wanti Rahayu ${ }^{2}$, Indra Kurniawan ${ }^{3}$ \\ Program Studi Informatika, Fakultas Teknik dan Ilmu Komputer, Universitas Indraprasta PGRI \\ Jalan Raya Tengah No 80, Kelurahan Gedong, Pasar Rebo, Jakarta Timur \\ setiawanheripratama@gmail.com ${ }^{1}$,wanti.reiku@gmail.com², Inkur.master@gmail.com ${ }^{3}$
}

\begin{abstract}
Abstrak
Aplikasi pemesanan makanan dan minuman berbasis java diharapkan dapat membantu dalam pemesanan yang sebelumnya masih secara manual menjadi terkomputerisasi. Aplikasi pemesanan makanan dan minuman pada rumah makan cepat saji D'besto merupakan suatu sistem yang memberikan kemudahan dalam melakukan transaksi pemesanan. Sehingga dapat mempermudah segala proses transaksi dalam pemesanan sehingga meminimalisir kesalahan dalam pencatatan data. Tujuan dalam pembuatan aplikasi pemesanan makanan dan minuman ini adalah dapat mempermudah pekerjaan dalam pencatatan dan pemesanan data ketersediaan menu data makanan dan minuman dan data penjualan agar pemesanan lebih mudah. Metode penelitian yang digunakan adalah metode grounded (grounded research). Selain itu peneliti juga menggunakan metode wawancara, dan kepustakaan untuk mendapatkan data lebih lengkap. Alat bantu analisis yang digunakan yaitu Diagram Konteks, Data Flow Diagram (DFD), relasi tabel dan Entity Relationship Diagram (ERD). Perangkat lunak yang digunakan dengan bantuan Bahasa pemrograman Java dan MySql sebagai database management guna terciptanya aplikasi pemesanan makanan dan minuman pada rumah makan cepat saji D'besto berbasis java. Hasil dari penelitian ini yaitu aplikasi dapat memberikan kemudahan kasir dalam pemesanan, pengolahan data dan laporan penerimaan agar lebih tepat dan akurat.
\end{abstract}

Kata Kunci: Pemesanan Makanan dan Minuman, Java, Aplikasi Kasir

\begin{abstract}
Java-based food and beverage ordering applications are expected to assist in bookings that were previously still manually computerized. D'besto Food and Beverage ordering application is a system that provides convenience in making booking transactions. So that it can facilitate any transaction process in the booking so as to minimize error in recording data. The purpose of making this food and beverage booking application is that it can facilitate work in recording and ordering data on the availability of food and beverage data and sales data to make booking easier. The research method used is the method of grounded. In addition, researchers also use interview methods, and libraries to get more complete data. The analysis tools used are context Diagram, Data Flow diagram (DFD), table relation and Entity relationship Diagram (ERD). The software is used with the help of the Java and MYSQL programming languages as the database management for the creation of food and beverage ordering applications in the Java-based fast food D'besto restaurant. The result of this research is that the application can provide convenience to the cashier in order, data processing and acceptance reports to be more precise and accurate.
\end{abstract}

Keywords: Food and Beverage Ordering, Java, Cashier Application

\section{PENDAHULUAN}

Kemajuan teknologi menuntut segala sesuatu pekerjaan manusia yang dalam keseharianya masih menggunakan cara manual dan dalam kinerjanya dirasa kurang efektif maka dapat dilakukan dengan teknologi yang maju. Pekerjaan yang masih menggunakan cara manual sebaiknya lebih ditingkatkan lagi menggunakan sistem komputerisasi. Dengan adanya sistem komputerisasi maka dapat membantu dalam menyelesaikan pekerjaan yang semula masih dilakukan secara manual (Utama, 2016). Pada proses penjualan makanan masih ditulis pada buku penjualan dan di ketik dalam mesin cash register saja. Sehingga dalam penyampaian pelaporan sangat tidak efisien karena masih dalam bentuk tulisan yang ditulis oleh kasir dibuku tulis. Oleh karena itu, perlu dibuat sistem aplikasi penjualan makanan pada rumah makan dengan menggunakan sistem yang terkomputerisasi. Sistem aplikasi dibuat supaya dapat membantu mempecepat proses penyelesaian pekerjaan (Nugraha et al., 2014). Pada proses penjualan, pembuatan struk secara otomatis, sehingga kasir tidak perlu menulis pada buku. 
Pemeriksaan hasil dari penjualan dapat diketahui dengan mudah tanpa harus mengecek satu per satu. Dengan demikian aplikasi dapat meningkatkan kinerja Rumah Makan Cepat Saji d'bestO.

Peneliti mempunyai tujuan merancang sebuah sistem untuk mempermudah pekerjaan dalam pencatatan data pemesanan, data ketersediaan menu, data makanan dan minuman, dan data penjualan agar pekerjaan lebih efektif dan efisien, membuat pengelolaan data untuk menyimpan dan pencarian data sehingga mempermudah pekerjaan serta mempermudah membuat laporan penjualan agar lebih akurat. Diharapkan penelitian ini bermanfaat untuk semua pihak yang telah membacanya maupun yang berhubungan langsung didalamnya, memberikan wahana pengetahuan yang sangat berarti bagi perkembangan sistem penjualan, dalam mempermudah kerja kasir serta menjadi bahan pengembangan untuk penelitian yang lebih lanjut.

\section{PENELITIAN RELEVAN}

Penelitian yang berjudul "Perancangan Sistem Aplikasi Penjualan Toko Komputer MASCOM Berbasis Dekstop", (Adi \& Sudjalwo, 2013). Universitas Muhammadiyah Surakarta, dengan kesimpulan bahwa struktur pengolahan data dan sistem informasi yang masih manual pada toko komputer MasCom membuat sistem berjalan tidak efektif, sehingga hal tersebut menimbulkan bermacam masalah. Masalah lain adalah sistem penjualan, pembelian, pemesanan barang, dan penyetokan barang yang masih sulit dalam pengorganisasiannya, sehingga menimbulkan kesalahan dalam penghitungan. Maka dengan itu dibuatlah sistem aplikasi penjualan berbasis java dengan tujuan agar pengelolaan dan pengolahan data tersimpan dengan sistem database untuk mencegah terjadinya redudansi yang dapat menyebabkan kerugian pada toko.

Penelitian yang berjudul "Aplikasi Pemesanan Makanan dan Minuman Restaurant Berbasis Client Server Dengan Platform Android dan Php Menggunakan Metode Centralized DBMS Architecture" (Utama et al., 2016) dengan kesimpulan bahwa dalam bisnis kuliner terdapat persaingan yang semakin meningkat setiap tahunnya, oleh karena itu setiap para pelaku usaha harus mencari strategi baru untuk mendongkrak jumlah pengunjung. Perkembangan teknologi sekarang ini memudahkan bagi para penggunanya dalam menjalankan segala kebutuhan yang dapat diterapkan dalam proses pemesanan makanan secara online. Adapun teknologi yang saat ini sedang berkembang adalah android.

\section{METODE PENELITIAN}

Metodologi penelitian yang digunakan oleh peneliti adalah metode grounded (grounded research) yaitu suatu metode penelitian pada fakta dan menggunakan analisis perbandingan dengan tujuan untuk menetapkan konsep, membuktikan teori, dan mengembangkan teori, pengumpulan dan analisis data dalam waktu yang bersamaan (Rahmah, 2014).

Melakukan interview dengan bagian pemesanan makanan, sesuai dengan bagian yang diteliti untuk mengumpulkan data yang dibutuhkan. Tujuan wawancara untuk memperoleh informasi yang lebih akurat dan lengkap, untuk menyusun sistem yang baru agar sesuai dengan kebutuhan sistem organisasi. Adapun hal-hal yang terjadi pertanyaan adalah seputar alur dan prosedur pemesanan makanan di Rumah Makan Cepat Saji d'bestO tersebut, sehingga dengan hasil wawancara antara pengguna dan pengembang dapat memperbaiki sistem yang ada.

Metode pengembangan sistem yang digunakan dalam penenelitian ini adalah menggunakan metode Waterfall, menurut (Pressman, 2015) waterfall adalah model klasik bersifat sistematis, berurutan dalam membangun software. Sebenarnya nama model ini adalah "Linier Sequential Model". Model ini dapat disebut juga dengan nama "classic life cycle" atau waterfall. Model ini melakukan pendekatan secara sistematis dan berurutan. Disebut waterfall karena setiap tahap demi tahap harus dilalui menunggu selesainya tahap sebelumnya dan berjalan secara berurutan.

Fase - fase dalam Waterfall Model menurut (Pressman, 2015): 


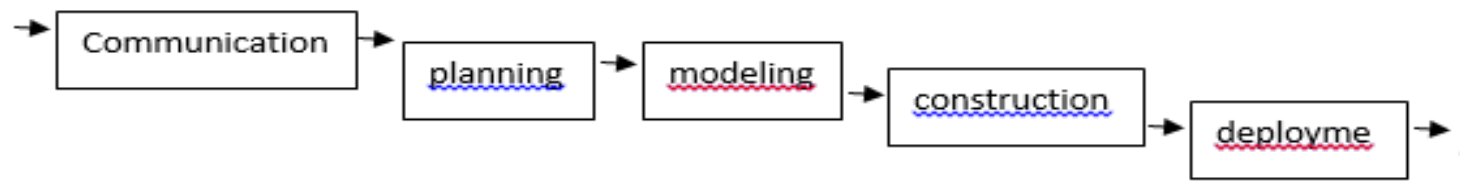

Gambar 1. Waterfall

Sumber : (Pressman, 2015)

Dalam model waterfall fase yang pertama adalah communication, sebelum memulai pekerjaan yang bersifat teknis, sangat diperlukan adanya komunikasi dengan customer demi memahami dan mencapai tujuan yang ingin dicapai. Hasil dari komunikasi tersebut adalah inisialisasi proyek, seperti menganalisis permasalahan yang dihadapi dan mengumpulkan data - data yang diperlukan, serta membantu mendefinisikan fitur dan fungsi software. Tahap berikutnya adalah tahapan perencanaan (planning) yang menjelaskan tentang estimasi tugas - tugas teknis yang akan dilakukan, resiko resiko yang dapat terjadi, sumber daya yang diperlukan dalam membuat sistem, produk kerja yang ingin dihasilkan, penjadwalan kerja yang akan dilaksanakan, dan tracking proses pengerjaan sistem. Setelah itu di lanjutkan ke fase modeling, tahapan ini adalah tahapan perancangan dan permodelan arsitektur sistem yang berfokus pada perancangan struktur data, arsitektur software, tampilan interface, dan algoritma program. Tujuannya untuk lebih memahami gambaran besar dari apa yang akan dikerjakan. Dan tahapan berikutnya adalah contruction ini merupakan proses penerjemahan bentuk desain menjadi kode atau bentuk/bahasa yang dapat dibaca oleh mesin. Setelah pengkodean selesai, dilakukan pengujian terhadap sistem dan juga kode yang sudah dibuat. Tujuannya untuk menemukan kesalahan yang mungkin terjadi untuk nantinya diperbaiki. Tahapan terakhir yaitu deployment merupakan tahapan implementasi software ke customer secara berkala, perbaikan software, evaluasi software, dan pengembangan software berdasarkan umpan balik yang diberikan agar sistem dapat tetap berjalan dan berkembang sesuai dengan fungsinya.

\section{HASIL DAN PEMBAHASAN}

\section{Alternatif Penyelesaian Masalah}

Solusi dari permasalahan sistem tersebut adalah dibuatnya sebuah perancangan sistem pengolahan data secara komputerisasi dimana data yang dibutuhkan untuk proses pesanan dapat mudah disimpan dan dicari, kelebihan dari sistem yang baru adalah berupa pengolahan data yang bersifat komputerisasi yang akan menghasilkan suatu informasi yang akurat dan efisien.

\section{Diagram Alir Data (DAD) Sistem yang Diusulkan}

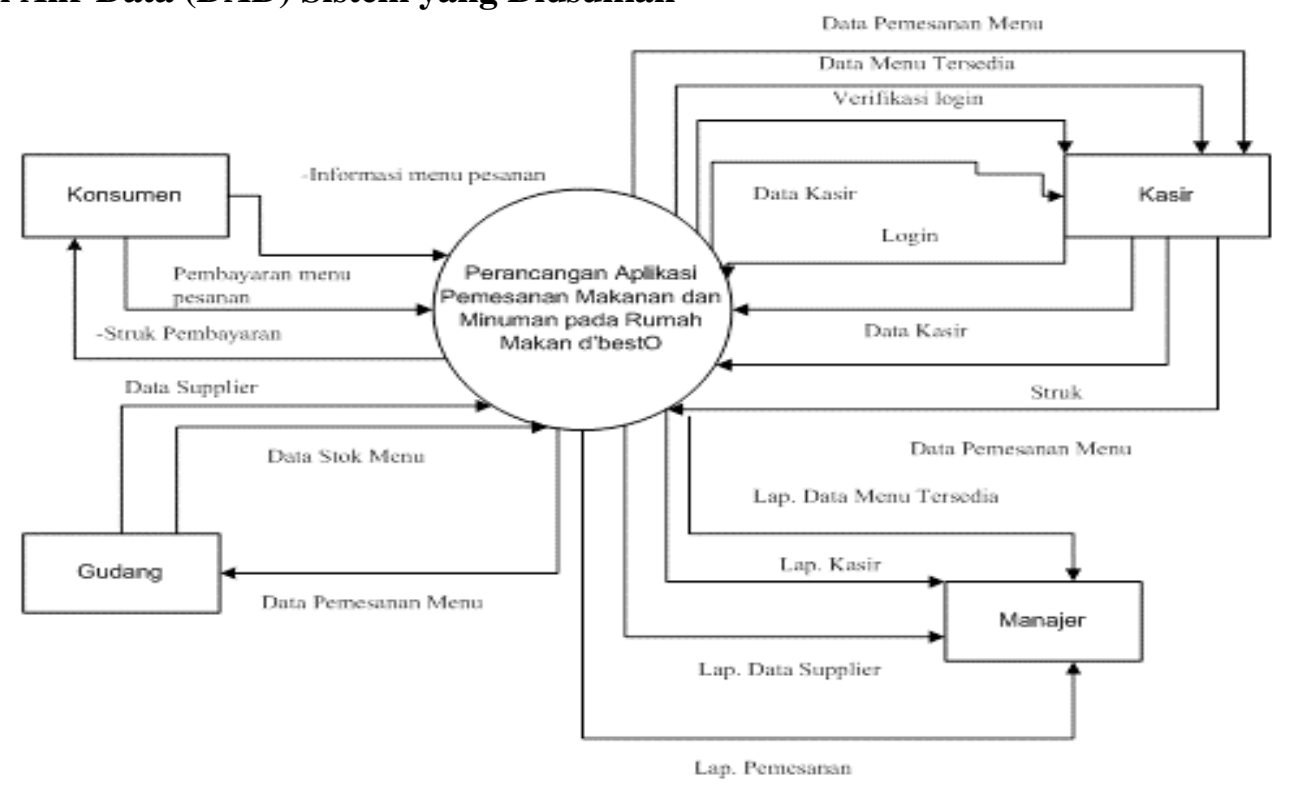

Gambar 2. Diagram Konteks Sistem Diusulkan 


\section{Entity Relationship Diagram (ERD)}

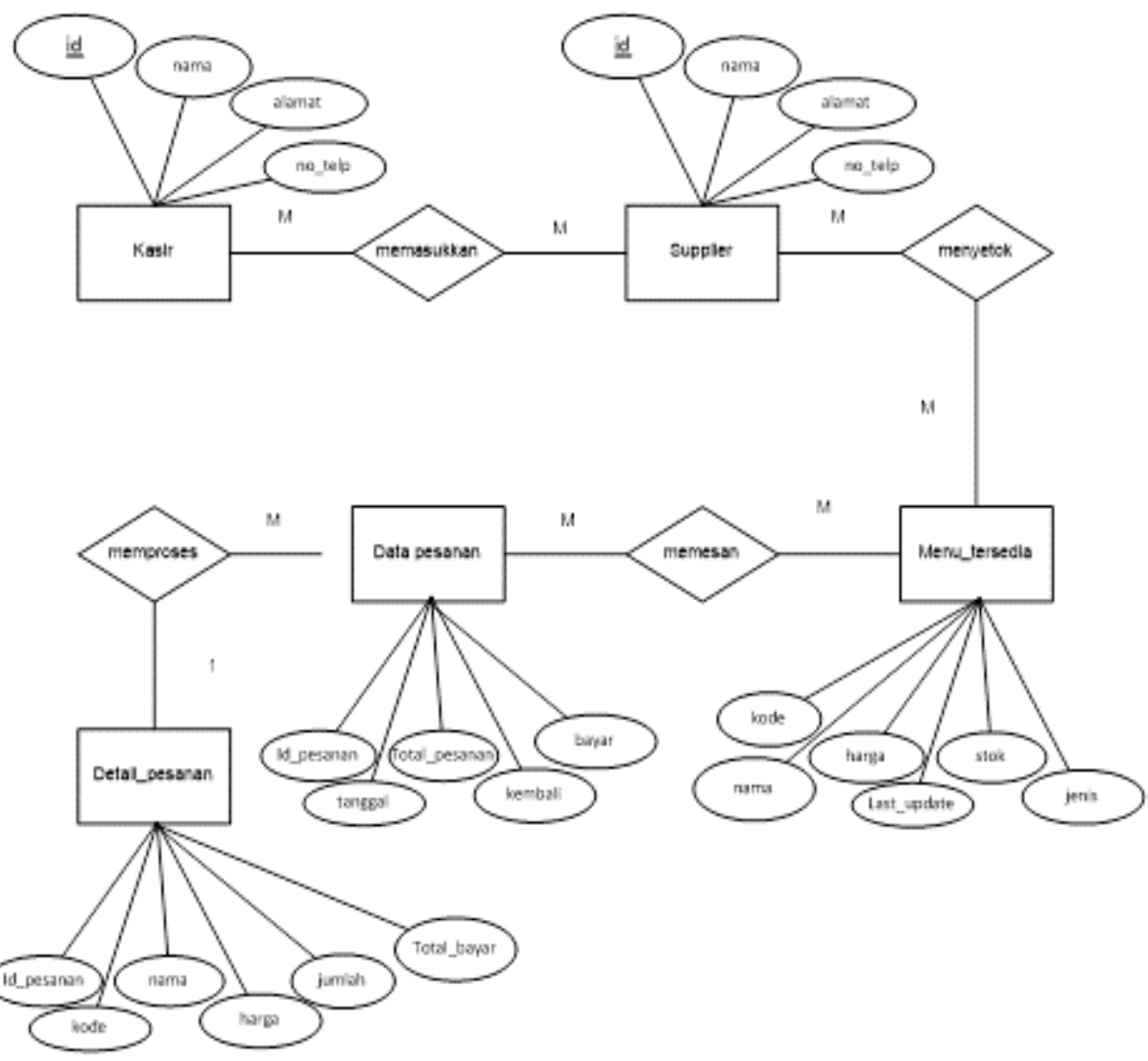

Gambar 3. Entity Relationship Diagram (ERD)

\section{Tampilan Layar}

Hasil perancangan tampilan layar antarmuka ini sebagai bentuk dari desain sistem yang telah dibuat.

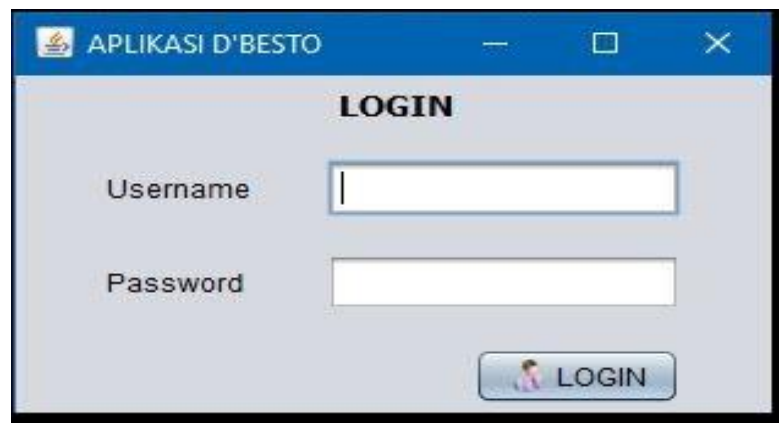

Gambar 4. Menu Login

Menu Login digunakan sebagai kata kunci sebelum kita memasuki tampilan menu utama. Program ini hanya dapat diakses untuk admin sebagai user yang sudah memiliki akun untuk mengakses. Sehingga segala data di dalam aplikasi tetap terjaga dengan baik kerahasiaannya. 


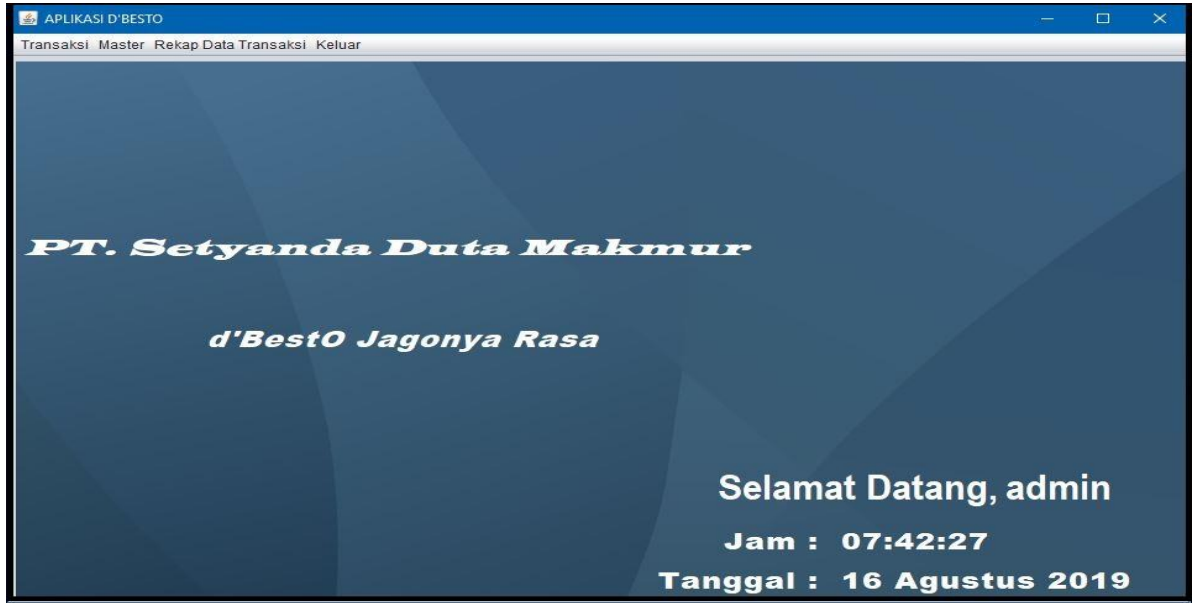

Gambar 5. Menu Utama

Pada gambar diatas merupakan tampilan menu utama pada aplikasi d'bestO yang dapat diakses setelah memasukkan username dan password pada menu Login.

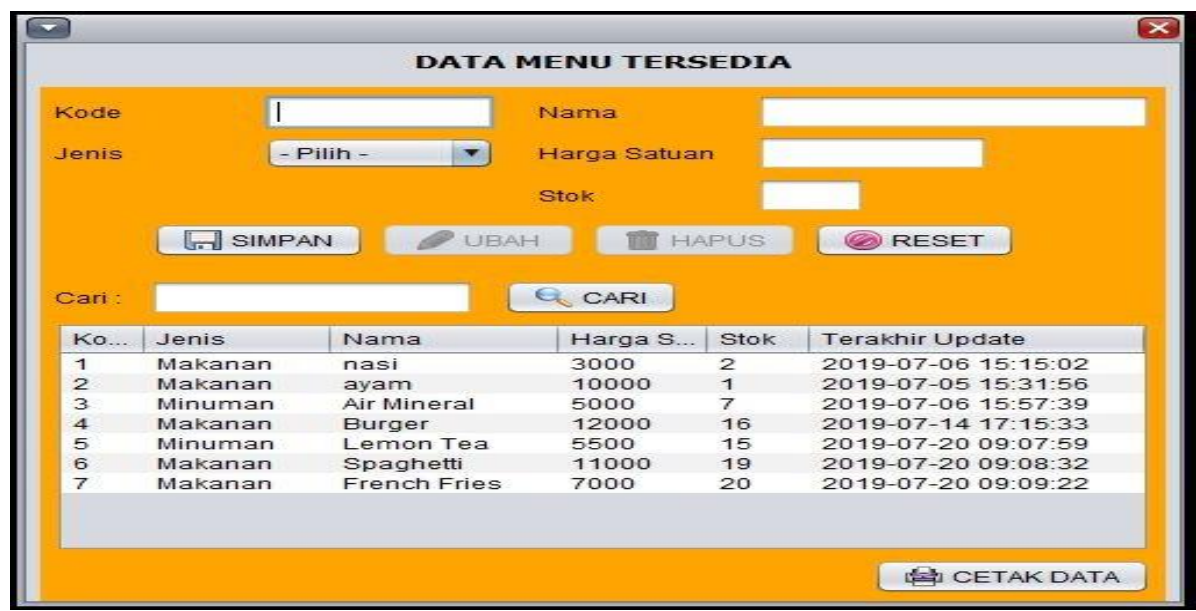

Gambar 6. Menu Tersedia

Dari gambar di atas, merupakan form untuk memasukkan data menu yang tersedia pada rumah makan cepat saji d'bestO berdasarkan jenis dan nama menu serta menampilkan jumlah stok.

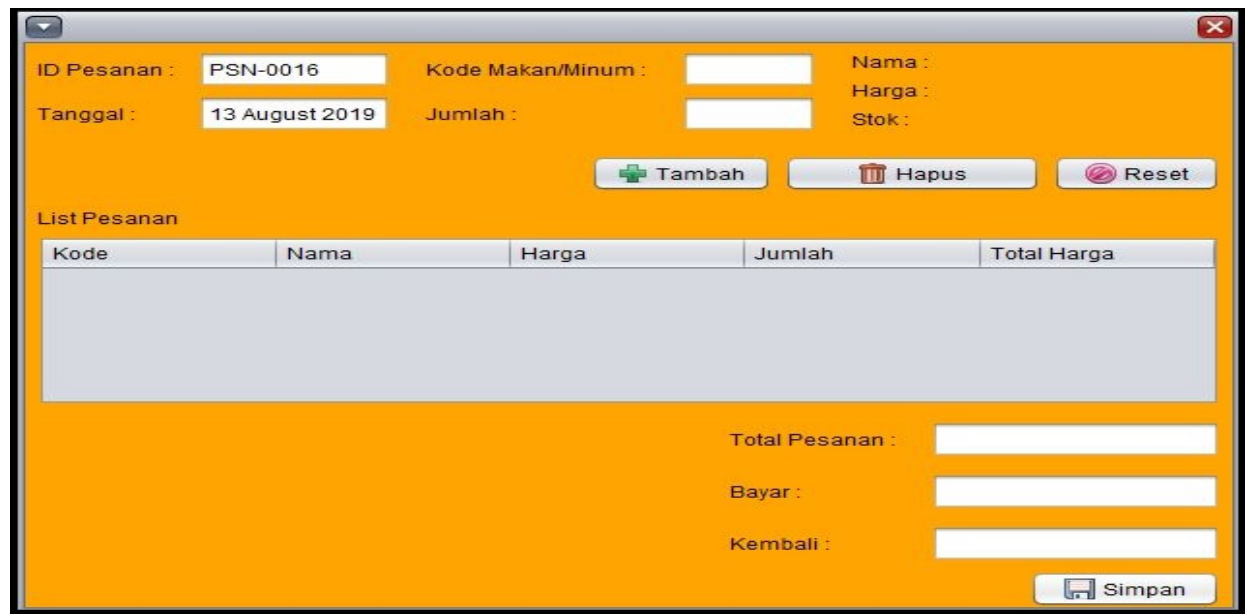

Gambar 7. Menu Transaksi Pemesanan 
Tampilan di atas merupakan tampilan form masukan untuk memasukkan segala transaksi data pesanan. Kemudian menghitung total pesanan yang harus dibayarkan oleh konsumen dan mengeluarkan struk pemesanan.

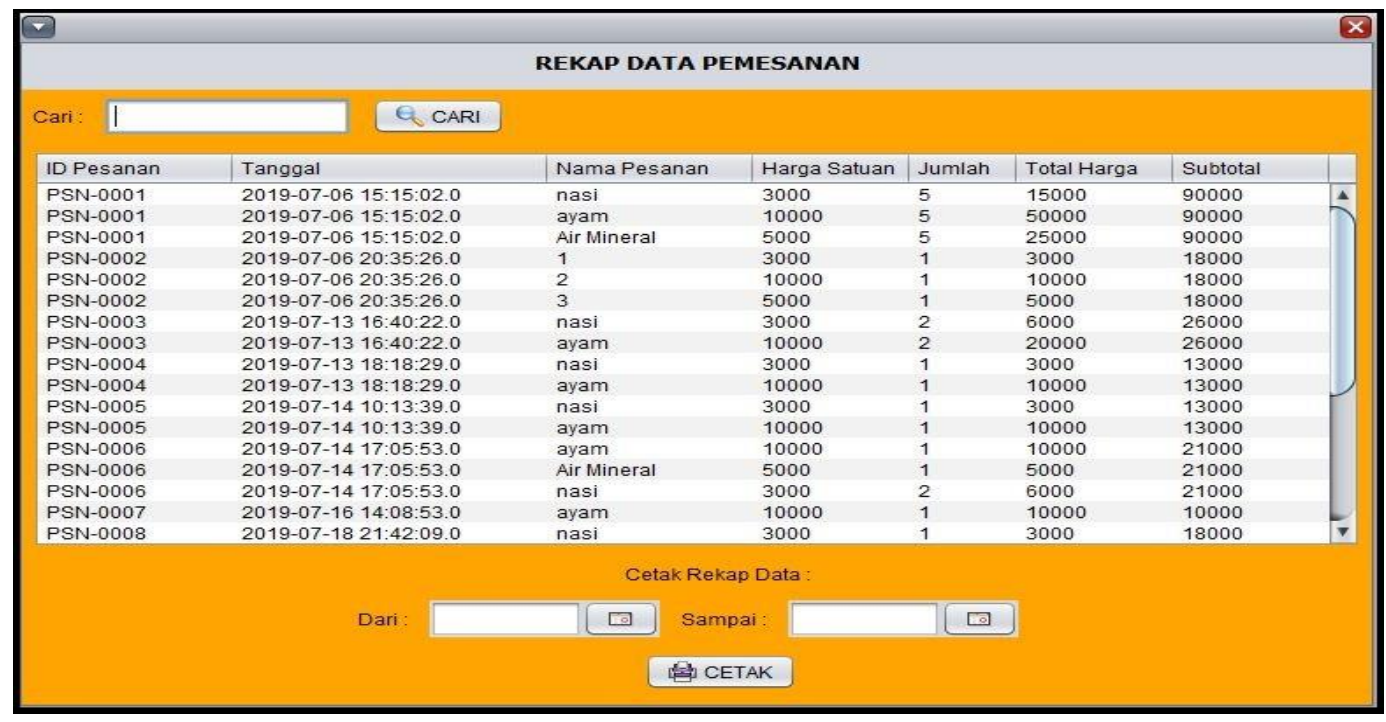

Gambar 8. Menu Rekap Pemesanan

Dapat dilihat dari gambar di atas, merupakan form untuk menampilkan rekap data seluruh transaksi pemesanan menu di rumah makan cepat saji d'bestO.

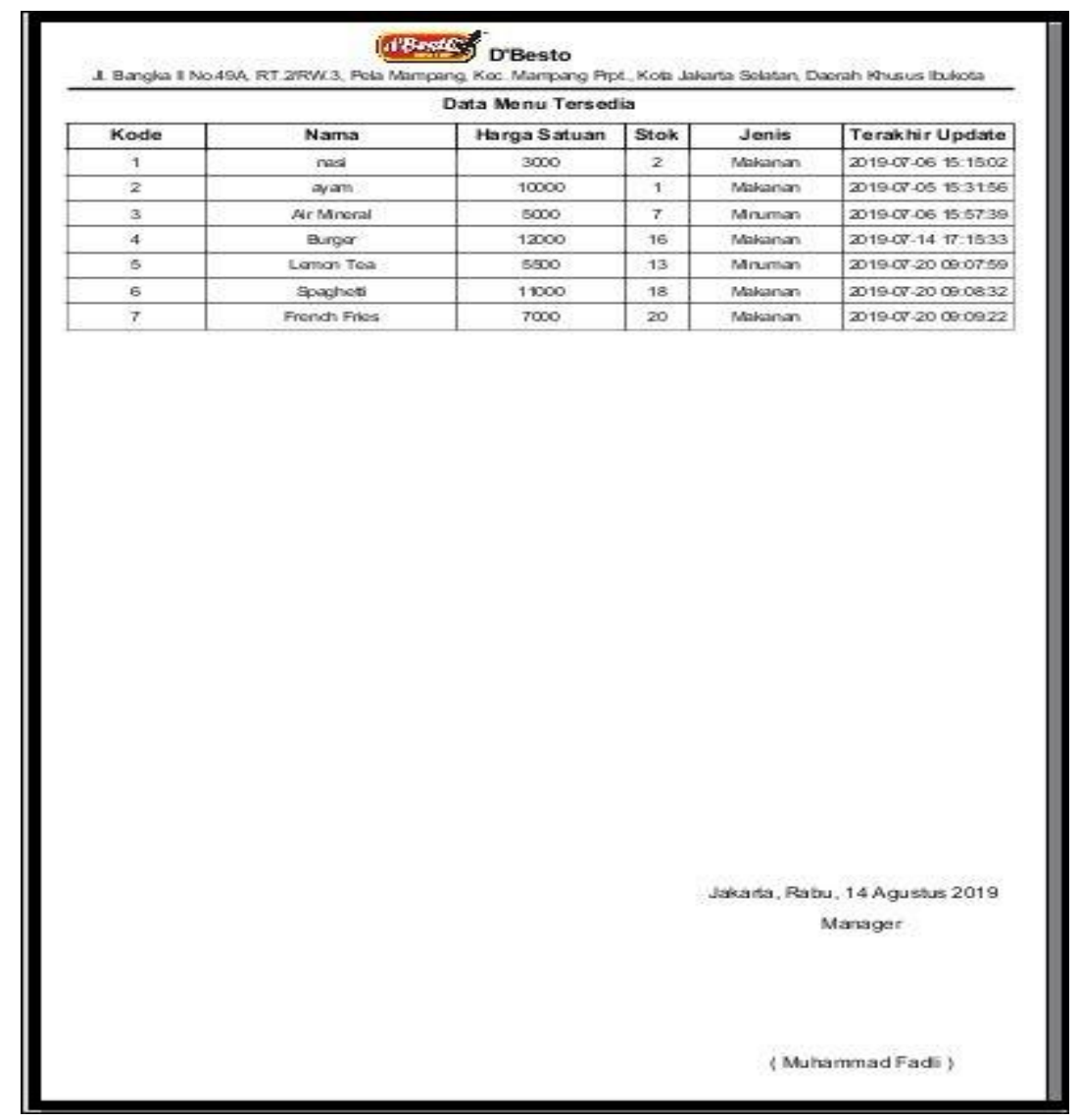

Gambar 9. Keluaran Data Menu Tersedia 
JRAMI (Jurnal Riset dan Aplikasi Mahasiswa Infarmatika)

Vol OI No Q3 Tahun 2020

e-ISSN : 2715-8756

Tampilan laporan ini digunakan untuk mencetak laporan data menu yang tersedia pada rumah makan cepat saji d'bestO berdasarkan stok yang ada.

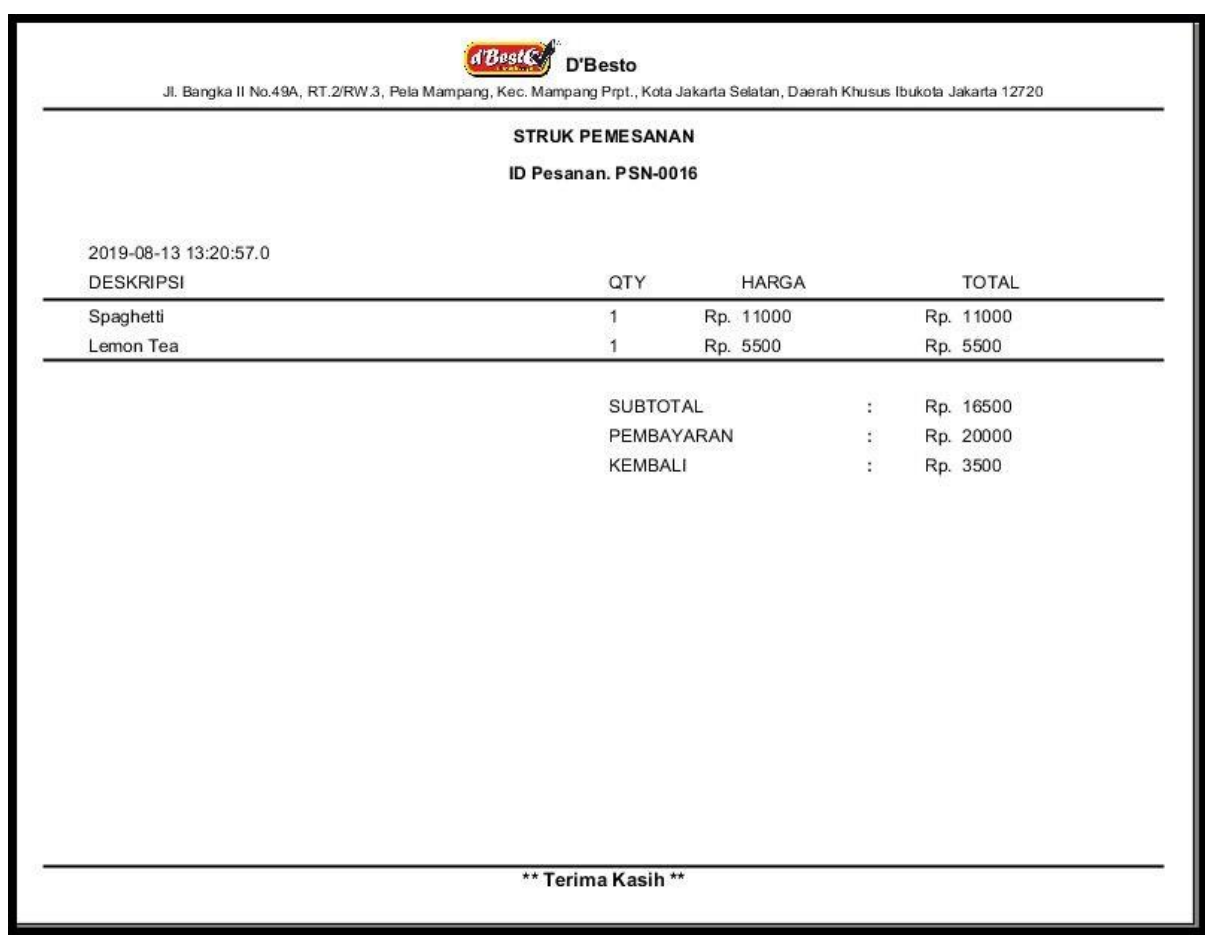

Gambar 10. Keluaran Struk Pesanan

Tampilan diatas merupakan cetakan keluaran struk pesanan yang akan diberikan kepada konsumen sebagai bukti transaksi pembelian.

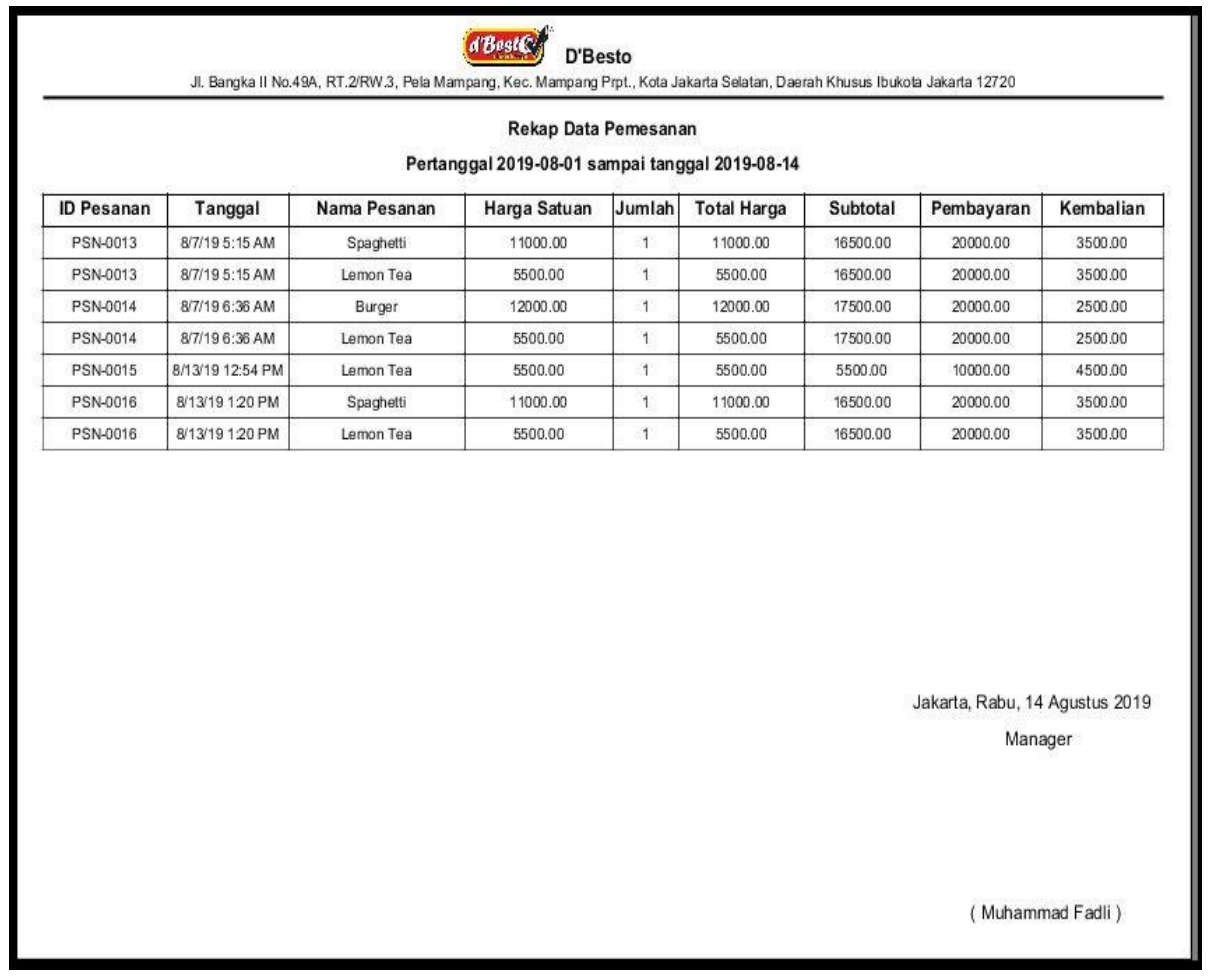

Gambar 11. Keluaran Struk Pesanan 
Tampilan laporan ini digunakan untuk mencetak rekap data transaksi pemesanan yang dilakukan kasir setiap harinya.

\section{SIMPULAN}

Berdasarkan hasil pembahasan dan penelitian, maka kesimpulannya adalah dapat membangun perancangan aplikasi pemesanan makanan dan minuman pada rumah makan cepat saji d'bestO, sehingga bisa lebih memudahkan kasir dalam proses pemesanan, mengurangi kekeliruan pencatatan, pendataan dan membantu menyajikan dalam pembuatan laporan sehingga lebih mudah dan cepat, karena data didalam database telah terintegrasi, dan peracangan aplikasi pemesanan dapat diterapkan pada rumah makan cepat saji d'bestO, dilakukan tahap implementasi yaitu setiap unit yang ada pada sistem diuji untuk fungsionalitasnya. Setelah pengujian masing-masing unit, semua unit program diintegrasikan ke sistem untuk diuji coba kegagalan dan eror. Jika masih ada yang eror maka akan di analisa kembali sesuai dengan keterangan dan tanda eror, dan diuji coba kembali pada sistem tersebut.

\section{DAFTAR PUSTAKA}

Adi, Sandi Pramono, Sudjalwo, Y. S. N. (2013). Perancangan sistem aplikasi penjualan toko komputer mascom berbasis desktop. Perancangan Sistem Aplikasi Penjualan Toko Komputer Mascom Berbasis Desktop.

Nugraha, A. P., Satoto, K. I., \& Martono, K. T. (2014). Aplikasi Pemesanan Makanan Berbasis Mobile Pada Rumah Makan "Lek Nonong." Jurnal Teknologi Dan Sistem Komputer. https://doi.org/10.14710/JTSISKOM.2.2.2014.175-180

Pressman. (2015). Library Binus. Software Engineering.

Rahmah, D. L. (2014). Perancangan Aplikasi Sisitem Perpustakaan Berbasis Web Pada PT. Dwi Pilar Pratama. Faktor Exacta.

Utama, D. (2016). Minuman Restaurant Berbasis Client Server Dengan P Latform Android. Jurnal Rekursif.

Utama, D., Johar, A., \& Coastera, F. F. (2016). Aplikasi Pemesanan Makanan Dan Minuman Restaurant Berbasis Client Server Dengan Platform Android Dan PHP Menggunakan Metode Centralized DBMS Architecture (Studi Kasus: Cafe Cempakoe Kota Bengkulu). Jurnal Rekursif. 